\title{
Drama and Role Playing in Teaching Practice: The Role of Group Works
}

\author{
Yağmur Çerkez ${ }^{1}$, Zehra Altınay ${ }^{1}$, Fahriye Altınay ${ }^{1}$ \& Elnara Bashirova ${ }^{2}$ \\ ${ }^{1}$ Faculty of Education, Near East University, Northern Cyprus, Mersin 10 Turkey \\ ${ }^{2}$ Faculty of Education, Eastern Mediterranean University, Northern Cyprus, Mersin 10 Turkey \\ Correspondence: Zehra Altınay, Faculty of Education, Near East University, Northern Cyprus, Mersin 10 Turkey. \\ E-mail: zehaltinay@gmail.com
}

\author{
Received: April 3, 2012 \\ Accepted: July 2, 2012 \\ Online Published: October 15, 2012 \\ doi:10.5539/jel.v1n2p109 \\ URL: http://dx.doi.org/10.5539/jel.v1n2p109
}

\begin{abstract}
The research study aims to explore the essence of group work in drama and role playing for teaching practice inline with the nature of collaborative learning process. This research study has qualitative nature by capturing experiences of volunteer ninety pre-service teachers about group works, gained skills from drama and role playing in their teaching practice within the scope of "Principles of Teaching and Methods" course in higher education. Therefore, self-report was employed in this research. Thematic analysis was used to analyze qualitative data based on key themes. The research findings revealed that pre-service teachers constructed both practical and pedagogical knowledge regarding group work and shed a light to their teaching practice.
\end{abstract}

Keywords: collaborative learning, group work, drama and role playing, teaching practice

\section{Introduction}

"A situation that two or more people learn or attempt to learn something together" is crucial to accomplish tasks simultaneously to enhance skills of learners (Dillenbourg, 1999, p. 1). Collaborative learning relies on a sense of acting for sharing creation and discovering for learning. It is a way of learning that learners come together by highlighting individual group members' abilities and contributions for their learning (Delucchi, 2004; Smith, 2004).

Significantly, both Piaget and Vygotsky provide ideas for social and individual aspects of development in collaborative learning. Piaget's theory focused mainly on individual aspects in cognitive. On the other hand, Vygotsky focused on individual development in the context of social interaction. For an advanced knowledge in higher education, learning based on social interaction and cognitive understanding, awareness is interrelated (Gillen, 2000). This emphasizes causal relationship between social interaction and individual cognitive change. In this respect, social constructivist approach refers development through collaborative learning process in respect to social interaction and active cognizing process through exchanging ideas, thoughts and lived experiences (Delucchi, 2004; Goldstein, 1993; Nelson, Deuel, Slavit, Kennedy, 2010). As collaborative learning attempts to look detailed how learners act in a group, it is inevitable not underestimate both Paiget and Vygotsky theories for the evolution of collaborative learning as a logical framework for learning and development (Pass, 2007). In collaborative learning, social interaction and individual cognitive change are the essential factors to shift socially constructed knowledge in order to transform knowledge into future experiences as a practice (Goodnough, 2007; Kapp, 2009; Todd, 1981).

Collaborative learning has six main categories which are group reward, positive connection, individual assessment, face-to face interaction, social assessments and equal success opportunity (Demirel, 1999). The harmonic practices of those categories provide a stance to achieve success in learning that it is kind of gaining awareness of pedagogical and practical knowledge in teaching practice for teacher education programmes.

Collaborative learning is an example of learning contexts in the knowledge construction process. Communicative practices and interaction within group contributes joint construction of knowledge (Saab, Joolingen \& Hout-Wolters, 2005)

Understanding collaborative learning processes has intensified need to analyze the group interaction in the context of learning goals. In collaborative learning, joint intellectual efforts are come together for a goal by 
searching for understanding, meaning, solutions and a creating product. In this respect, it is essential to address importance of group work in order to analyze the practical implications of collaborative learning as it is credible element for co-construction of knowledge in higher education practices (Kapp, 2009).

As collaborative refers joint production of ideas, learners exchange their thoughts and then generate shared meaning or understanding through their joint efforts. In fact, creating a repertoire of collaboration and micro-teaching session for practice is inevitable in teacher education programmes (Beck, 2008). In this respect, the study of Staples (2007) gives an insight on how pre-service teachers function in a group for repertoire of the learning and teaching practices within the framework of collaborative inquiry.

Furthermore, it needs to put an emphasis on active collaborative learning which learners who are actively engaged in learning to achieve desirable outcome in teaching practice and co-construction of pedagogical knowledge in their subject field (Li, Dong, Huang, 2009). In this respect, they recognize to interact and discuss actively engaged within collaborative learning. Therefore, collaboration and interaction between pre-service teachers promote deep learning through gaining different perspectives and providing opportunities for negotiation to their better performance (Brett, Nagra, 2005; Oxford, 1997; Marin, Benarroch, Gomez, 2001).

As teacher development implies the process of professionalism, attitudinal development and functional development are crucial elements in teacher education. In this respect, teaching practice in any subject within the classroom context is crucial for pre-service teachers in order to enhance their professional knowledge to internalize pedagogical knowledge inline with practice and collaboration (Wood, Bennett, 1998).

Collaborative learning supports the skills development of pre-service teachers within their teaching practice (Kontopoulos, Ford, Roth, 2007; Raelin, Raelin, 2006; Todd, 1981; Wood, O’Malley, 1996). They gained self efficacy and implementation trough group works and they enhance peer reflection based on drama and role playing in their teaching (Crumbley, Smith, Smith, 1998; Delucchi, 2007; Gunderson, Moore, 2008; Pazos, Micari, Light, 2010). The position of drama and role playing has impact to practice future professional experience. It aims to make perception education and creativity in teaching methods for pre-service teachers. Drama and role playing is one of the teaching methods which it is also taught within "Principles of Teaching and Methods" course for the pre-service teachers in teacher education programmes. At the same time, it can provide a ground in teaching practice for pre-service teachers to internalize pedagogical and practical knowledge.

In this respect, group work is also crucial within the preparation of drama and role playing for teaching practices thus contributes professional knowledge (Taylor, 2000). Drama and role playing facilitates learning and provides enthusiasm to practice knowledge and work together (Crumbley, Smith, \& Smith, 1998). It is used as an instructional tool to reinforce both pedagogical and professional knowledge. In this respect, it supports teamwork and interpersonal skills of learners (Cohen, Ruff, 1995; Saab, Joolingen, \& Wolters, 2009).

The study of Harris and Bretag (2003) give an insight on a cycle of reflection in collaborative learning. In this respect, drama and role playing of pre-service teachers through group works in "Principles of Teaching and Methods" course supports increasing in quality learning outcomes.

In this research study, interaction model was employed which is indicated below:

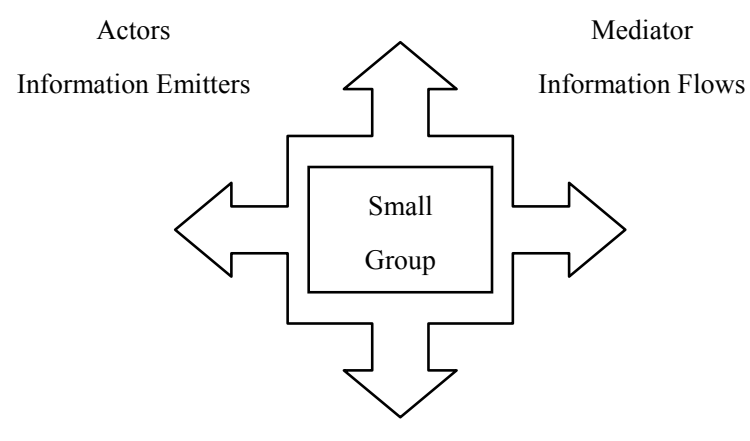

Actors and Mediator

Sending and Receiving Information

Figure 1. Interaction Model for Learning 
This models roots the group work based on collaboration that pre-service teachers exchange ideas and experiences in relation to subject matter as teaching principles and methods (Capponi, Nussbaum, Marshall, Lagos, 2010). As the words 'collaborative learning' describe a situation in which particular forms of interaction among people are expected to occur, which would trigger learning mechanisms, but there is no guarantee that the expected interactions will actually occur, instruction of the particular course need to be designed to enrich interaction (Dillenbourg, 1999, p. 5). In this respect, drama and role playing has a role to foster awareness of future teaching practice as well as a result of group work and interaction within small groups.

The aim of this research study is to explore the impact of group work for drama and role playing within teaching practice. For this specific research focus, the following research questions are set and provide a road map throughout the research process. Research questions are indicated as following:

Q1. How do pre-service teachers perceive group work?

Q2. What are the skills that collaborative learning process fosters for pre-service teachers?

Q3. How do pre-service teachers perceive their groups in a metaphoric way?

Q4. To what extent, does drama and role playing support teaching practice of pre-service teachers within group work?

\section{Material and Methods}

\subsection{Chosen Research Design: Qualitative Research}

In this research study, qualitative research design was employed. This research design allows researchers to construct a picture of experiences that research participants provided dense data about their experiences. As this research study emerged from themes and interpretation of pre-service teachers on group work, gained skills, drama and role playing in teaching practices, interpretations, experiences within inductive process justify the reason of choosing roots of qualitative research within the research process (Creswell, 2009).

\subsection{Chosen Research Approach}

As case study is a qualitative research strategy in which researcher explores a program, event, activity, process within in-depth investigation. In this respect, case study was used as an approach of this inquiry in which researchers attempted to explore in-depth activity and process with capturing individuals' experiences and perceptions within a larger spectrum (Creswell, 2009). In this respect, researchers attempted to undertake three classes of pre-service teachers who have studied "Principles of Teaching and Methods" course as a case of this research in higher education practice.

\subsection{Research Process and Ethics}

Research process was an inductive process in this research study. Pre-service teachers were selected purposively as research participants. This research study was carried out the period of time from the course of "Teaching Principles and Methods". 90 pre-service teachers participated to this research study voluntarily from the Pre School Teacher Education and Classroom Teacher Education programmes. This course was the mass course that course instructors approach student centered teaching strategies within a frame of collaborative learning. In this respect, the mode of course was based on group works, drama and role playing while pre-service teachers' practice teaching in the classroom context in relation to pedagogical and practical knowledge. They formed a small group which includes three members and they worked for drama and role playing in order to practice each teaching methods within the course hours. Informed consent form was given to pre-service teachers that they signed these forms to exhibit their willingness to be part of this research. In addition, back translation was done to keep the credibility of the inductive research.

\subsection{Data Collection Technique and Analysis}

In order to gather data, self-report was employed to explore the understanding of pre-service teachers about group work, their gained skills and the impact of drama and role playing in their teaching practices within collaborative learning process. In analyzing data, thematic analysis was used by concentrating on matrix strategy. Basic themes that are group work, metaphoric interpretations of their groups, gained skills from group work, drama and role playing in teaching practices were remarked to provide credible research findings and discussion (Creswell, 2009).

\section{Results and Discussion}

Research findings and discussion were driven based on themes in relation to research questions which were about the understanding of group work, skills gained through group work, metaphoric interpretation of 
pre-service teachers about group work, skills gained from the drama and role playing activities and what it added to them. For each theme, the findings were summarized in tables and discussed under main themes.

\subsection{Understanding of "Group Work"}

The first main theme was about the pre-service teachers' the understanding and awareness of what group work is (See Table 1). The self-report of prospective teachers $(\mathrm{N}=90)$ revealed 5 sub-themes which are working together, interaction, students' development, team spirit and responsibility in relation to awareness of group work.

Table 1. Understanding of "group work"

\begin{tabular}{ll}
\hline 1. & Working together \\
a. & Studying together \\
b. & Researching \\
c. & Presenting a certain topic/subject \\
\hline 2. & Interaction \\
a. & Collaboration \\
b. & Cooperation \\
c. & Communication \\
d. & Exchange of ideas \\
\hline 3. & Effective method for students' development \\
a. & Socialization \\
b. & Developing problem solving skills \\
c. & Developing cognitive, sensory, emotional \\
skills \\
d. & Self-confidence \\
\hline 4. & Team spirit \\
\hline 5. & Responsibility \\
\hline
\end{tabular}

The first sub-theme that emerged from the responses of the participants is "working together", which involves studying together, researching and presenting a certain topic/subject with a group of people. The participants remarked what group work is in many ways:

"Students with different individual differences come together and produce a common work."

"Group work means a few people that work together as equals and present the work as a whole."

"It is working on a certain topic and presenting it in the classroom."

"It is the outcome of effective and productive work done together."

"Group work is researching on a given topic and presenting creative ideas."

"It is sharing the subject, researching and then presenting the research."

"Gathering together and presenting a project."

"A few people research and do a common work together."

"Doing together and reaching to a conclusion."

The second sub-theme that emerged from the understanding of group work is "interaction". This highlighted that interaction covered collaboration, cooperation, communication and exchange of ideas. Almost all participants expressed interaction as following:

"It is the cooperation and exchange of ideas between individuals."

"Group work involves collaboration and exchange of information." 
"Group working requires reaching to a common point of view through discussion."

"It involves communication and cooperation skills."

"Group work is learning how to cooperate and developing communication skills."

"It is the exchange of ideas and knowledge and being able to take a common decision through cooperation."

"This is the work that comes out of exchange of ideas."

"Group working is the exchange of ideas on a given subject and producing a common work through effective communication."

Participants also expressed their understandings of group work as "an effective method for students' development". This includes socialization, developing problem-solving skills, developing cognitive, emotional, and sensory skills and developing self-confidence. Almost all pre-service teachers expressed the understanding of group work as an effective method for development in many ways:

"It is a good and effective method for students' development."

"It improves self-confidence in the student."

"Group work activities enable developing cognitive, emotional and sensory skills through communication."

"Group working helps socialization."

"Group work activities help us improve problem-solving skills."

The fourth sub-theme is team spirit. The participants agreed the meaning of group work as team spirit in below:

"Group working creates a team spirit."

"A successful group work requires working as a team."

"It is moving as a whole."

"It means community and it requires team spirit."

The last sub-theme which emerged from self-reports of the participants is "taking responsibility". The pre-service teachers expressed responsibility in many ways:

"It is being more responsible."

"Group work requires undertaking responsibility."

"Group work is trusting each other and taking responsibility at the same time."

In summary, pre-service teachers' understandings of group work revealed that group work reminds them working together with a group of people, study, research and present a topic/subject together. Therefore, it can be understood that the participants believe that working in groups require working together with other people. Another result is that interaction is important in understanding group work activities. In relation to this, the participants agreed that group work activities involve effective collaboration, cooperation, communication and exchange of ideas between students. The next result in terms of the pre-service teachers' understanding of group work is that it is an effective method for students' socialization and it improves self-confidence. In addition, the participants reflected that group work reminds them that it develops problem-solving skills and cognitive, sensory and emotional skills. In addition, the pre-service teachers' interpretation revealed that their understanding of group work involves team spirit which means that it creates an atmosphere of working together and studying in harmony. Finally, the participants highlighted that having responsibility and doing the work in discipline is an important aspect of group work activities.

\subsection{Skills Gained through Group Work Activities}

In the second theme, the pre-service teachers were remarked about the skills they gained from the group work activities which can be seen in Table 2. The self-report of participants revealed 7 main sub-themes which are: working together equally and sharing workload, interpersonal relations and communication skills (socializing, interaction, speaking, expressing ideas, cooperation, sharing, listening to others, empathy and respecting), self-confidence, responsibility, researching and studying skills, leadership and critical and creative thinking skills. 
Table 2. Skills gained through group work

\begin{tabular}{lll}
\hline 1. & Working together equally and sharing the work load \\
\hline 2. & Interpersonal relations and communication skills \\
a. & Socializing & f. Sharing \\
b. & Interaction & g. Listening others \\
c. & Speaking & h. Empathy \\
d. & Expressing ideas & i. Respecting others' ideas \\
e. & Cooperation & \\
\hline 3. & Self-confidence & \\
\hline 4. & Responsibility & \\
\hline 5. & Researching and study skills \\
\hline 6. & Leadership & \\
\hline 7. & Critical and creative thinking \\
\hline
\end{tabular}

The first sub-theme of the skills gained from the group work activities was working together equally. Almost all pre-service teachers expressed this in many ways as follows:

"We learned that group working requires working equally."

"We learned working together equally."

"I learned how to work together."

"I learned that if everyone works equally, group work is more effective."

"Group work activities develop skills of working together."

"It enables active involvement of all students and learning how to work together."

The second sub-theme which emerged from in-depth data was interpersonal relations and communication skills. This involves socializing, interaction, speaking, expressing ideas, cooperation, sharing, listening to others, empathy and respecting skills. The pre-service teachers expressed these skills in many ways as follow:

"We gained skills like socializing, sharing ideas, interacting and communicating. In addition, we learned expressing ourselves more easily."

"It helps cooperation and socialization."

"I gained cooperation skills. It developed my relations with my friends. I didn't have any interaction with some of my friends in the classroom for three years. With the help of group work, we developed our dialogues and relations."

"It helped exchange of ideas between us. It also decreased my embarrassment in front of others."

“...getting to know each other."

“... friendships strengthen."

"It develops cooperation and exchange of ideas."

"Provides opportunity for getting to know other friends"

"Individuals socialize and they get to know each other."

"Being respectful, listening, and expressing ideas."

"Develops communication skills, collaboration and sharing."

"Collaboration, sharing, waiting for your turn and respecting, listening and more efficient exchange of knowledge."

"Developing relationships and reaching to a common target through discussion."

"Being in collaboration and harmony."

"Provides socialization developing interpersonal skills and exchange of ideas." 
"It develops listening skills and being in collaboration with others. Develops empathy skills."

The third sub theme which emerged from self-reports about the skills gained from the group work was self-confidence. The pre-service teachers remarked their skills about self-confidence as follows:

"Group work increases self-confidence abilities."

“... increases self-confidence and being able to decide together."

The fourth sub-theme is responsibility. The pre-service teachers agreed that responsibility is one of the gained skills from the group work as they reflected their interpretations as following:

"Group works tell us how to work in a systematic way and how to do research in discipline."

"It taught us to be responsible."

"Individuals in the group behave more careful because of responsibility."

"My responsibility increased."

The fifth sub-theme was research and study skills. Almost all pre-service teachers expressed this in many ways:

"Group works developed our researching and studying skills."

"We realized how we learn better."

The sixth sub-theme which emerged from the responses of the participants is leadership skills. The pre-service teachers expressed this in many ways as follows:

"Together with the high level thinking, it helps develop leadership."

The final theme which emerged from the responses of the participants was critical and creative thinking. The participant expressed this as following:

"I can say my creativity developed."

"I learned looking at things from a different perspective and it develops critical thinking skills."

"Critical thinking skills develop and it helps one develop individual abilities and develops creative thinking skills."

In summary, the interpretation of findings about the skills gained through group work activities revealed that working together equally and sharing the work load is one of the main skills. This means that pre-service teachers believe that they gain the skills of how to share the work load while working with other people and trying to work equally. In line with this, they also reflected that group work activities improve their interpersonal relations and communication skills. These main headings involve socializing, interacting, speaking, expressing their ideas freely, cooperating, sharing, listening to others, empathy and respecting others. The findings also revealed that pre-service teacher think that their self-confidence and responsibility skills develop while doing group work activities. In addition, they remarked that because they have to research and read about the subject, their research and study skills develop through preparing the group work activities for the pedagogical knowledge. Finally, the participants also highlighted that leadership skills develop and that the group work activities develop their critical and creative thinking skills which these are highly crucial for advanced knowledge in higher education practices. This is because, they agreed, the group work activities involve different people with different characters and this leads to discussion and thus, it forces them to think critically and create new ideas while constructing both pedagogical and practical knowledge (Delucchi, 2007; Goodnough, 2007; Kapp, 2009).

\subsection{Metaphoric Interpretation of Group Work}

Almost all pre-service teachers reflected their interpretation of group work through metaphors (Elmholdt, 2003). Metaphoric interpretation of the pre-service teachers about the group work activities revealed multi-dimensional perspectives. Although, this refers to a variety of responses, these can be summarized under similar headings inline with reasons of underlying particular metaphor (See Table 3). 
Table 3. Metaphoric interpretations of group work

\begin{tabular}{lll}
\hline Attentive, curious, thinking & Different people, working equal, having different thoughts \\
\hline Parsley & One for all, all for one & Impression \\
Curiosity & Toleration & Comment \\
Brain storm & Rainbow & Influence \\
Grasshopper & Union & Knowledge \\
& Colorful & Success \\
& Unity & Target \\
& All one & \\
\hline
\end{tabular}

One of the main sub-themes can be seen under the heading of "attentiveness, curiosity and thinking". The participants expressed this in many ways:

"I would name my group Parsley because it requires being attentive and having answers to everything."

"Curiosity. Because the first step of learning is curiosity."

"Grasshopper. Because we become active like a grasshopper and do our best."

"Brain storm. Because people with different characters think and create ideas."

The next sub-theme emerging from the metaphoric interpretations mainly involves different people having different ideas and thoughts. The pre-service teachers reflected this in many ways as follows:

"I would name it all for one, one for all because we all work equally and together."

"Union. Because if only we work together as a union, we become successful."

"Rainbow. Because the group members create different ideas."

In summary, metaphoric interpretation of the pre-service teachers showed that they interpreted group work as being attentive, curious and forcing to thinking. In order to express these meanings, they used metaphors such as parsley, brainstorm, curiosity and grasshopper as metaphors. The other metaphoric interpretation exhibited that they interpreted group work as requiring different people from different backgrounds and working together with these people to create divergent and common thoughts. They used metaphors such as rainbow, union, colorful, all one and impression to express their interpretations and experiences.

\subsection{Skills Gained through the Method of Drama and Role Playing}

The final theme was about the skills that pre-service teachers gained through the method of drama and role playing and what these activities added to them (See Table 4).

Table 4. Skills gained from the method of drama and role playing

\begin{tabular}{ll}
\hline 1. & More effective learning \\
a. & Permanent learning \\
b. & Becomes more memorable \\
c. & Easier understanding \\
\hline 2. & Increases self-confidence and decreases excitement \\
\hline 3. & Listening, communication, management and observation skills \\
\hline 4. & Creating better relations \\
\hline
\end{tabular}

The participants agreed which their reflection can be summarized in 4 main sub-headings which are more effective learning (Involving permanent learning, becoming more memorable, and easier understanding); self-confidence and excitement; skills such as listening, communication, management, observation; and creating better relations.

The first sub theme was more effective learning process. In this respect, the participants expressed this in many 
ways as following:

"Because it is based on visual activities, it becomes difficult to forget."

"We saw that when the lecture is visual, it becomes more effective and it helps the subject to be more memorable."

"It helps us understand better and strengthens our knowledge on the topic."

"We realized that learning by doing in more effective and more permanent."

"It is more probable that it will be more memorable when we use visual application in the classroom."

The second main theme is self-confidence and excitement. The pre-service teachers expressed that their self-confidence increased while their excitement decreased when they are talking in front of a community. They reflected their experiences as following:

"Our shyness decreased through talking in front of others."

"It helped us overcome our shyness."

"I learned to express my ideas without being fearful."

"A better involvement to the classroom and expression of ideas without being fearful."

"It develops self-confidence in those who make the presentation."

“... balancing our excitement."

"It decreases our excitement while talking in front of a community."

The third sub-theme can be summarized under the heading of listening, communication, management and observation skills. The pre-service teachers expressed their experiences as follows:

"Helped better communication to be established."

"I learned observation and how important the listening activities are."

"It added to me the skill of good listening."

"It helps us see others' mistakes and learn from them."

"Besides expressing myself, I developed classroom management skills."

The fourth sub-theme emerging from self-reports of the pre-service teachers is creating better relations between their friends and developing their critical friendship bonds. The participants expressed their experiences in many ways:

"We established better relations with our friends."

"It helps bonding among students."

"I observed the importance of friendship."

In summary, the findings about the skills gained from the method of drama and role playing and what it added to them showed that the pre-service teachers think the drama and role playing is more effective ways of teaching and learning since it involves permanent learning, easier understanding of the topic and it helps the subject to be more memorable. They reflected this is because the visual and auditory methods are more effective in creative this result. In addition, they underlined that drama and role playing activities increased their self-confidence while also decreasing their excitement when talking in front of a group of people. This is line with the result that these activities add them effective listening, communication, classroom management and observation skills. Finally, the pre-service teachers remarked that drama and role playing activities done in the classroom develop their friendship relations and that they created a better bonding with their friends while working together because they talked, discussed, thought and enjoyed while learning and constructing pedagogical and practical knowledge (Cohen, Ruff, 1995).

\section{Conclusions}

The research remarked and discussed the findings about the impact of collaborative learning process which covered drama and role playing sessions through group works for pedagogical and practical knowledge construction within "Principles of Teaching and Methods" course as a mass course for teaching practice. In addition, the research highlighted how an interaction model practiced in teacher education courses within higher education practices. In this respect, this inductive process revealed how theoretical knowledge transform into practice based on collaboration, sense of lived experience and negotiation for further learning experiences 
(Hargreaves, 2007). Significantly, collaborative learning environment facilitates pedagogical and practical awareness of teaching practice which this research highlighted positive influence of drama and role playing through group works for co-construction knowledge within the framework of collaboration and interaction model (Hargreaves, 2007; Kontopoulos, Ford, Roth, 2007). Regarding Vygotsky and Piaget's perspectives for learning and development, this research revealed how both perspectives shed a light in higher education context and practices for the advanced knowledge. Therefore, social interaction and peer reflection within learning and development are inevitable elements within collaborative and negotiable process for co-construction of knowledge and skills development (Gillen, 2000; Pass, 2007; Oxford, 1997; Wood, Bennett, 1998).

In respect to the aim of this research, how pre-service teachers perceive group work, which skills are developed as a result of collaborative learning process, how they internalize this process with underlying metaphors, to what extend drama and role paying support teaching practice were demonstrated and discussed (Raelin, Raelin, 2006). Regarding an interaction model, drama and role playing through establishing group work and collaboration facilitated to gain multiple perspectives and empathy skill as these are inevitable for professional awareness. The collective effort of small group also exhibited awareness of subject matter knowledge and enhancement of communication, critical thinking and team work skills as this research undertook (Pazos, Micari, Light, 2010). In this respect, pre-service teachers exchanged ideas and experiences in relation to drama and role playing through group work for learning outcomes of the course thereby this also fostered their awareness of future teaching practice beside pedagogical, practical knowledge and skills development (Capponi, Nussbaum, Marshall, Lagos, 2010).

As collaborative learning environment was not familiar to pre-service teachers that almost all course instructors approached classical teaching sessions in this research context, this learning journey provided gaining in-depth knowledge and enjoyment from learning as it is resulted in better learning and excitement to involve in group work and discussion. Significantly, drama and role playing through group works enabled students to be central of instruction and lead them to construct their own knowledge through multi-dimensional perspectives within active learning environment (Gunderson, Moore, 2008). Social interaction between students and contemporary practices of teaching and learning process within a frame of social constructivism are the critical dimensions for professional growth. In this respect, these dimensions are multifaceted by providing awareness of knowledge, development of skills and teaching practice (Staples, 2007).

In terms of group work, the research highlighted that having high level of responsibility, team spirit, interaction and working together are interrelated components that a group of people can demonstrate collective effort to achieve learning. In addition, research exhibited that involving group work activities create a repertoire of working together at the same time sharing responsibilities. Furthermore, interpersonal communication skills such as socialization, listening, speaking, empathy, etc. are developed (Todd, 1981). Metaphoric interpretations confirmed how pre-service teachers perceive group work and what group work activities contributed them (Elmholdt, 2003). In this respect, it can be highlighted that pre-service teachers had an excitement to involve in collaborative learning process and they were aware of its contributions to their personal and professional growth in this research. Significantly, the research revealed that drama and role playing is an effective learning tool for the students that they gain self-confidence and establish critical friendship bonds. Furthermore, they develop communication, management and observation skills (Cohen, Ruff, 1995; Crumbley, Smith, Smith, 1998; Pistole, Kinyon, Keith, 2008).

In this respect, this research sheds a light to internalize interaction model and social constructivism in teacher education field. Collaborative drama and role playing learning environment provides reflection, negotiation, discussion and team work skills. In addition, this learning environment supports pedagogical and practical knowledge. Furthermore, it facilitates to internalize teaching practice. Although the research provided highly positive outcomes of this learning environment, longitudinal comparative studies and multiple data collection techniques need to be conducted to gain more insight about the impact of interaction model and its limitations.

\section{References}

Beck, S. (2008). The teacher's role and approaches in a knowledge society. Cambridge Journal of Education, 38, 465-481. http://dx.doi.org/10.1080/03057640802482330

Brett, P., \& Nagra, J. (2005). An investigation into students' use of a computer based social learning space: lessons for facilitating collaborative approaches to learning. British Journal of Educational Technology, 36, 281-292. http://dx.doi.org/10.1111/j.1467-8535.2005.00457.x

Capponi, M. F., Nussbaum, M., Marshall, G., \& Lagos, M. E. (2010). Pattern discovery for the design of face-to-face computer-supported collaborative learning activities. Educational Technology \& Society, 13(2), 
40-52.

Cohen, M. B., \& Ruff, E. (1995). The use of role play in field instructor training. Journal of Teaching in Social Work, 11(1), 85-110. http://dx.doi.org/10.1300/J067v11n01_07

Creswell, J. W. (2009). Research design: Qualitative, quantitative and mixed methods approaches. London: SAGE.

Crumbley, D. L., Smith, K. T., \& Smith, L. M. (1998). Teaching note educational novels and student role-playing: a teaching note. Accounting Education, 7(2), 183-191. http://dx.doi.org/10.1080/096392898331252

Delucchi, M. (2004). Assessing the impact of group projects on examination performance in social statistics. Teaching in Higher Education, 12, 447-460. http://dx.doi.org/10.1080/096392898331252

Delucchi, M. (2007). The efficacy of collaborative learning groups in an undergraduate statistics course. College Teaching, 54, 244-248. http://dx.doi.org/10.3200/CTCH.54.2.244-248

Dillenbourg, P. (1999). What do you mean by collaborative learning? In P. Dillenbourg (Ed.), Collaborative-learning: Cognitive and Computational Approaches (pp.1-19). Oxford: Elsevier.

Elmholdt, C. (2003). Metaphors for learning: Cognitive acquisition versus social participation. Scandinavian Journal of Educational Research, 47, 115-131. http://dx.doi.org/10.1080/00313830308616

Gillen, J. (2000). Versions of Vygotsky. British Journal of Educational Studies, 48, $183-198$. http://dx.doi.org/10.1111/1467-8527.t01-1-00141

Golstein, G. S. (1993). Using a group workshop to encourage collaborative learning in an undergraduate counselling course. Teaching of Psychology, 20, 108-110. http://dx.doi.org/10.1207/s15328023top2002_10

Goodnough, K. (2007). Fostering teacher learning through collaborative inquiry. The Clearing House: A Journal of Educational Strategies, Issues and Ideas, 79, 88-92.

Gunderson, D. E., \& Moore, J. D. (2008). Group learning pedagogy and group selection. International Journal of Construction Education and Research, 4(1), 34-45. http://dx.doi.org/10.1080/15578770801943893

Hargreaves, E. (2007). The validity of collaborative assessment for learning. Assessment in Education: Principles, Policy \& Practice, 14, 185-199.

Harris, H., \& Bretag, T. (2003). Reflective and collaborative teaching practice: Working towards quality student learning outcomes. Quality in Higher Education, 9(2), 173-79. http://dx.doi.org/10.1080/13538320308151

Kapp, E. (2009). Improving student teamwork in a collaborative project-based course. College Teaching, 57, 139-143. http://dx.doi.org/10.3200/CTCH.57.3.139-143

Kontopoulos, O., Ford, V., \& Roth, S. (2007). Collaborative teaching and learning in a networked course setting. Community \& Junior College Libraries, 14, 63-73. http://dx.doi.org/10.1300/J107v14n01_07

Li, Y., Dong, M., \& Huang, R. (2009). Toward a semantic forum for active collaborative learning. Educational Technology \& Society, 12, 71-86.

Marin, N., Benarroch, A., \& Gomez, E. J. (2001). What is the relationship between social constructivism and Piagetian constructivism? An analysis of the characteristics of the ideas within both theories. International Journal of Science Education, 22, 225-238. http://dx.doi.org/10.1080/095006900289840

Nelson, T. H., Deuel, A., Slavit, D., \& Kennedy, A. (2010). Leading deep conversations in collaborative inquiry groups. The Clearing House: A Journal of Educational Strategies, Issues and Ideas, 83, 175-179.

Oxford, R. L. (1997). Constructivism: Shape-shifting, substance, and teacher education applications. Peabody Journal of Education, 72(1), 35-66.

Pass, S. (2007). When constructivists jean Piaget and lev Vygotsky were pedagogical collaborators: a viewpoint from a study of their communications. Journal of Constructivist Psychology, 20, 277-282.

Pazos, P., Micari, M., \& Light, G. (2010). Developing an instrument to characterise peer-led groups in collaborative learning environments: assessing problem-solving approach and group interaction. Assessment \& Evaluation in Higher Education, 35, 191-208. http://dx.doi.org/10.1080/02602930802691572

Pistole, M. C., Kinyon, J., \& Keith, C. B. (2008). Group experiential learning with undergraduate nursing students: an interdisciplinary approach. The Journal for Specialists in Group Work, 33, 161-178. http://dx.doi.org/10.1080/01933920801977348

Raelin, J. A., \& Raelin, J. D. (2006). Developmental action learning: Toward collaborative change. Action 
Learning: Research and Practice, 3, 45-67. http://dx.doi.org/10.1080/14767330600574615

Saab, N., Joolingen, W. R., \& Out-Wolters, B. H. A. M. (2009). The relation of learners' motivation with the process of collaborative scientific discovery learning. Educational Studies, 35, 205-222. http://dx.doi.org/10.1080/03055690802470357

Smith, S. A. (2004). Designing collaborative learning experiences for library computer Classrooms. College \& Undergraduate Libraries, 11, 65-83. http://dx.doi.org/10.1300/J106v11n02_06

Staples, M. (2007). Supporting Whole-class collaborative inquiry in a secondary mathematics classroom. Cognition and Instruction, 25, 161- 217. http://dx.doi.org/10.1080/07370000701301125

Taylor, A. M. (2000). (Auto)biography and drama: Life history work with adult returners to education. Research in Drama Education: The Journal of Applied Theatre and Performance, 5(2), 249-261.

Todd, F. (1981). Developing teaching skills for collaborative learning. Studies in Higher Education, 6, 91-96. http://dx.doi.org/10.1080/03075078112331379569

Wood, E., \& Bennett, N. (1998). Teachers' theories of play: constructivist or social constructivist? Early Child Development and Care, 140(1), 17-30. http://dx.doi.org/10.1080/0300443981400103

Wood, D., \& O'Malley, C. (1996). Collaborative learning between peers. Educational Psychology in Practice: Theory, Research and Practice in Educational Psychology, 11(4), 4-9. http://dx.doi.org/10.1080/0266736960110402 